«Системні технології» 2 (127) 2020 «System technologies»

DOI 10.34185/1562-9945-2-127-2020-07

УДК $542.3+519.6$

\author{
В.Б. Мазуренко
}

\title{
СПОСІБ ВИЗНАЧЕННЯ КІЛЬКОСТІ РІДИНИ В НАХИЛЕНІЙ ЄМНОСТІ НА ОСНОВІ ТРІАНГУЛЯЦІЇ ДЕЛОНЕ
}

Анотація. Розглянуто задачу перерахунку даних вимірювання рівня та куту нахилу в кількість рідини всередині ємності. Запропоновано спосіб їі вирішення на основі тріангуляції Делоне. Показано, що для практичних цілей даний спосіб єуніверсальним.

Ключові слова: вимірювання кількості речовини, об'ємна тріангуляція, інформаційновимірювальна технологія

Постановка проблеми. Серед проблем, пов’язаних 3 проведенням технічних вимірювань, є проблема визначання кількості рідини всередині нахиленої ємності на основі показань датчика рівня. Вона є окремим випадком більш загальної проблеми, що стосується визначання кількості рідини всередині рухомої ємності [1]. Проблема полягає в тому, що градуювальна характеристика датчика, яка пов’язує показання датчика та кількість рідини в ємності, отримується за умов, коли ємність встановлена в штатному положенні, тоді як вимірювання проводяться в нештатному, нахиленому положенні. Через це в результатах вимірювання з’являється додаткова похибка. Ця похибка залежить від кута нахилу, місця встановлення датчика та від форми ємності. Вона може бути повністю відсутня, якщо форма ємності є такою, що площа її поперечного зрізу не залежить від висоти, на якій проведено зріз, а датчик встановлено точно в геометричному центрі поперечного зрізу ємності. Наприклад, циліндрична ємність $з$ датчиком, встановленим на її повздовжньої осі. Проте, на практиці такі умови проведення вимірювань забезпечуються далеко не завжди. Найбільш складним випадком є вимірювання у придонній зоні нахиленої ємності. Площа поперечного зрізу, що перерізує лише стінки ємності, та зрізу, що перерізує ще й дно, суттєво різняться

(C) Мазуренко В.Б., 2020 
«Системні технології» 2 (127) 2020 «System technologies»

(рис. 1). Тому використання градуювальної характеристики для визначення кількості рідини практично втрачає сенс: за невідомого куту нахилу отримане значення характеризується високим рівнем невизначеності. Саме такі умови мають місце під час вимірювання кількості палива в паливних баках транспортних засобів: кут нахилу баків морського судна, автомобіля або літака весь час змінюється. Важливо відзначити, що невизначеність результатів вимірювання зростає одночасно з зростанням потреби в достовірності отриманої інформації про залишки палива, як раз в той час, коли паливо закінчується та знаходиться в придонній області бака. Цю невизначеність можна значно зменшити, якщо використовувати дані про нахил ємності. Проте навіть за наявності даних про кут нахилу разом з даними про висоту рівня рідини всередині ємності перерахунок цих даних в кількість рідини є доволі складною й невирішеною на сьогодні задачею.

Мета дослідження. Метою дослідження, результати якого представлені в даній статті, є пошук шляхів вирішення проблеми визначення кількості рідини всередині нахиленої ємності. Стаття присвячена тій частині проблеми, яка пов'язана з перерахунком даних вимірювання висоти рівня рідини та куту нахилу в кількість рідини всередині ємності.

Аналіз останніх досліджень і публікацій. В роботі [1] проведено детальний аналіз стану вирішення проблеми визначання кількості рідини всередині рухомої ємності й у тому числі - нахиленої ємності. Встановлено, що дана проблема в цілому залишається невирішеною. Загальне рішення, що дозволяє зменшити похибку вимірювання до значень, які відповідають вимірюванням в штатному положенні, в науковій та технічній літературі наразі не представлене. Також вказано, що інструментальними засобами проблема може бути вирішена лише частково, й для вирішення проблеми в цілому необхідні пошук способів обробки вимірювальної інформації і створення відповідних інформаційновимірювальних технологій.

Викладення основного матеріалу дослідження. Задача перерахунку виміряних висоти рівня рідини та куту нахилу в кількість рідини всередині ємності з геометричної точки зору зводиться до задачі знахо- 
«Системні технології» 2 (127) 2020 «System technologies»

дження об’єму тримірної фігури, точніше кажучи - об’єму зрізаної фігури. В якості фігури виступає ємність, зріз проводиться по площині поверхні рідини, об’єм рідини - це об’єм ємності, що знаходиться нижче поверхні зрізу. Розглянемо можливі способи вирішення задачі на основі відомих методів.

Спершу розглянемо спосіб на основі використання градуювальної характеристики датчика. Використання градуювальної характеристики датчика $є$ основним методом визначення кількості рідини в стаціонарних ємностях, тобто - за відсутності нахилу [2]. Пов’яжемо жорстко осі $X$, $Y, Z$ з ємністю (разом з датчиком), а осі $X_{H}, Y_{H}, Z_{H}-$ з землею таким чином, щоби вони співпадали, а осі $Z$ та $Z_{H}$ були б направлені вертикально, водночас найнижча точка ємності знаходилася би на нульовій позначці. Якщо площі поперечних зрізів відомі, то градуювальна характеристика ємності, тобто залежність об’єму рідини всередині ємності від висоти рівня $z$, виміряного датчиком вздовж осі ємності $Z$, визначається формулою:

$$
V(z)=\int_{0}^{z} S(z) d z
$$

де $S(z)$ - площа поперечного горизонтального зрізу ємності на висоті $z$. Градуювальна характеристика датчика може бути визначена як шляхом розрахунку по формі ємності, так й експериментально. Тепер нахилимо ємність (рис. 1).
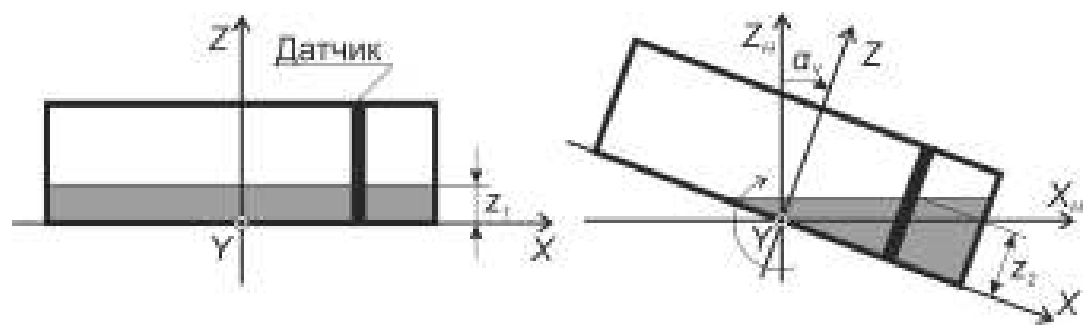

Рисунок 1 - Змінення показань датчика рівня від z1 до z2 під дією нахилу ємності (поворот навколо осі Ү на кут $\alpha_{y}$ ) за незмінної кількісті рідини

Поперечний зріз, залишаючись горизонтальним (це - поверхня рідини) вже не $є$ перпендикулярним до осі $Z$. Залежність $S(z)$ зміниться, відповідно зміниться залежність $V(z)$. За наявності в ємності тої ж самої кількості рідини $V$ датчик замість висоти рівня $z_{1}$ буде показувати вже 94 
«Системні технології» 2 (127) 2020 «System technologies»

інше значення $-z_{2}$. Коли має місце нахил ємкості, то необхідно враховувати, що площа поперечного зрізу є функцією не одної змінної (висоти $z)$, а трьох: $S=S(z, \alpha)=S\left(z, \alpha_{x}, \alpha_{y}\right)$, де $\alpha$ - кут нахилу ємності, тобто кут проміж пов’язаною 3 землею віссю $Z_{H}$ (нерухомою вертикаллю), та пов’язаною з ємністю віссю $Z$, який в проекціях на рухомі осі координат $X$ та $Y$ має дві складові: $\alpha_{x}$ - кут обертання навколо осі $X$, та $\alpha_{y}$ - кут обертання навколо осі $Y$. Це означає, що замість залежності $V(z)$ має використовуватися залежність $V\left(z, \alpha_{x}, \alpha_{y}\right)$, оскільки градуювальна характеристика в такому випадку має вигляд: $V\left(z, \alpha_{x}, \alpha_{y}\right)=\int_{0}^{z} S\left(z, \alpha_{x}, \alpha_{y}\right) d z$. Таким чином, для того, щоб за показаннями датчика рівня та інклінометра визначити кількість рідини в нахиленій ємності необхідно визначати експериментально, або розрахунковим шляхом, а потім весь час зберігати в табличному вигляді, або у вигляді набору коефіцієнтів функцію трьох змінних для всіх можливих кутів нахилу та висот рівня рідини. Такий спосіб вирішення задачі є громіздким, вкрай затратним, через це на практиці не застосовується.

Розглянемо інший спосіб. Якщо кут нахилу є незмінним, й він відомий, то об’єм під площиною поверхні рідини можна визначити суто геометричними методами. Формули для знаходження об’ємів таких типових фігур як циліндр, еліпсоїд, паралелепіпед, піраміда, конус та таке інше відомі, вони наводяться у довідниках [3]. Якщо відомо, через яку точку проходить поверхня рідини (а це є сукупність показань та координат датчика рівня), а також під яким кутом проходить поверхня (а це є показання вимірювача нахилу ємності), то по відомим формулам можна розрахувати об’єм фігури під зрізом, при умові, якщо форма ємності є типовою фігурою, або може бути розкладена на дві-три типові фігури. Саме такий спосіб представлено у роботі [4]. Проте цей спосіб має суттєві недоліки. Він потребує участі спеціаліста в аналізі створених зрізом форм $з$ метою вибору потрібних формул та формування початкових даних, тобто він не універсальний та в загальному випадку не піддається автоматизації. В випадку підвищення складності форми ємності він стає занадто громіздким. Більш того, в загальному випадку - випадку ємності 


\section{«Системні технології» 2 (127) 2020 «System technologies»}

довільної форми, він не може бути застосований. Тому цей метод запропоновано для використання лише в окремих випадках, як то: обрахування градуювальної характеристики ємності для зберігання палива, яка за час експлуатації нахилилася на деякий фіксований кут по причині, наприклад, зсуву фундаменту.

Ще один геометричний спосіб теоретично може бути застосований до ємностей, які мають форму багатогранника [5]. Для його використання потрібно знати довжину ребер багатогранника. Проте цей метод відрізняється великою розрахунковою складністю, оскільки потребує пошуку коренів поліному ступеня, рівного кількості вершин. Він також потребує участі спеціаліста. Тому цей спосіб також не може бути рекомендований для використання в вимірюваннях.

До універсальних способів визначення об’єму фігур відноситься обчислювальний метод на основі тріангуляції. Він дозволяє знаходити приблизне значення об’єму фігури довільної форми. Якщо ж фігура початково є багатогранником, то тоді отримане значення є точним. Суттєвою превагою цього методу є можливість проведення розрахунку методами аналітичної геометрії, й це дозволяє побудувати алгоритми автоматичної обробки даних вимірювань. До недоліків можна віднести достатньо високу обчислювальну складність алгоритмів побудови тріангуляції. Ідея методу тріангуляції полягає в тому, що будь-який об’ємний багатогранник можна розбити на деяку сукупність тетраедрів. Об’єм тетраедра розраховується за простою формулою, тож розрахувавши об’єми усіх тетраедрів можна знайти об’єм усього багатогранника. Якщо ж маємо фігуру довільної форми, то її з заданою точністю можна представити у вигляді багатогранника і таким чином обчислити її приблизний об’єм. Метод широко використовується в геоінформаційних системах, системах автоматизованого проектування, для моделювання рельєфу, в системах машинного зору та таке інше. Наявні переваги, такі, як універсальність та легка алгоритмізація, обумовлюють перспективу ефективного його застосування для перерахунку даних вимірювання висоти рівня рідини та куту нахилу ємності в кількість рідини всередині ємності. Слід добавити, що методи тріангуляції введені в деякі системи програмування в вигляді 96 
«Системні технології» 2 (127) 2020 «System technologies»

відповідних функцій та об’єктів. Не зосереджуючись на опису методів тріангуляції, які достатньо висвітлені в науковій літературі (для прикладу наведемо роботу [6]), відзначимо тільки загальні моменти. По-перше, існує поверхнева, або двомірна (2-D), тріангуляція - це розбиття плоскої геометричної фігури на трикутники. Розбити фігуру можна багатьма способами. Серед усіх способів виділяється тріангуляція Делоне для заданої множини точок - це коли для будь-якого трикутника всі точки за винятком точок, які є його вершинами, лежать поза окружністю, що описана навколо цього трикутника. Тріангуляція Делоне є єдиною. Вона максимізує суму радіусів вписаних кіл та мінімальний кут серед усіх кутів всіх побудованих трикутників, тим самим уникають «тонких» трикутників. Завдяки цим властивостям тріангуляція Делоне найкраще відповідає потребам вирахування площі та об’єму. Крім двомірної також існує тримірна (3-D), або об’ємна, тріангуляція, завдяки якій проводиться розбиття об’ємної геометричної фігури на тетраедри. Для 3-D тріангуляції так само існує 3-D тріангуляція Делоне, яка має ті ж самі властивості, що й двомірна, тільки по відношенню до тримірних величин. Для вирішення поставленої задачі найбільш підходить саме тримірна тріангуляція Делоне. Вона й використовується в запропонованому способі визначення кількості рідини. Розглянемо його детально.

Вихідні дані, умови та припущення для застосування запропонованого способу визначення кількості рідини в нахиленої ємності наступні:

1. 3 ємністю пов’язана декартова система координат XYZ. За відсутності нахилу ємності, ось $Z$ направлено вертикально догори. Датчик вимірювання висоти рівня рідини жорстко встановлено всередині ємності. Вимірювальна вісь датчика розташована паралельно осі $Z$. Координа-

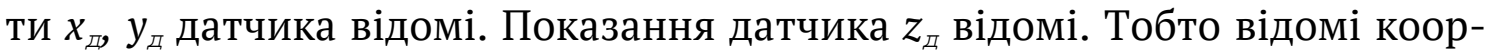
динати точки $\left(x_{\text {д }}, y_{\text {д }}, z_{\text {д }}\right)$, через яку проходить площина поверхні рідини.

2. Кут нахилу ємності, тобто кут відхилення нерухомої вертикалі від осі $Z$, виміряно: кути обертання нерухомої вертикалі навколо осі $X$ та осі $Y: \alpha_{x}$ та $\alpha_{y},-$ відомі. Таким чином, відомий вектор нормалі до поверхні рідини $\left(n_{x}, n_{y}, n_{z}\right)$ в системі координат $X Y Z$, пов’язаній з ємністю. 
«Системні технології» 2 (127) 2020 «System technologies»

3. Форма ємності відома: відомі координати усіх вершин об’ємного багатогранника, якій або точно відповідає формі ємності, або є ïi достатнім приближенням. Це координати $\left(x_{i}, y_{i}, z_{i}\right) i=1, N$, де $N$-кількість вершин багатогранника.

Послідовність розрахунку наступна.

1. Будуємо тріангуляцію Делоне по вершинам багатогранника, який представляє форму ємності. Це можна зробити за допомогою або стандартних можливостей системи програмування (наприклад, об’єкт delaunayTriangulation системи MATLAB), або алгоритму, наведеному в [6]. Отримуємо сукупність тетраедрів.

2. Використовуємо рівняння площини у вигляді:

$$
A x+B y+C z+D=0
$$

та визначаємо коефіцієнти для площини поверхні рідини:

$$
A_{p}=n_{x} ; \quad B_{p}=n_{y} ; \quad C_{p}=n_{z} ; \quad D_{p}=-\left(A_{p} x_{\text {д }}+B_{p} y_{\text {д }}+C_{p} z_{\text {д }}\right)
$$

3. Перебираємо усі ребра усіх тетраедрів, та знаходимо всі точки перетину ребер тетраедрів площиною поверхні рідини. Для цього спочатку знаходимо коефіцієнт $\lambda$, в пропорції до якого дана площина розбиває ребро на частини:

$$
\lambda_{j}=-\frac{A_{p} x_{j 1}+B_{p} y_{j 1}+C_{p} z_{j 1}+D_{p}}{A_{p} x_{j 2}+B_{p} y_{j 2}+C_{p} z_{j 2}+D_{p}}
$$

де $\left(x_{j 1}, y_{j 1}, z_{j 1}\right)$, та $\left(x_{j 2}, y_{j 2}, z_{j 2}\right)$ - координати двох вершин $j$-того ребра тетраедра. Якщо $\lambda_{j}$ більше нуля, то точка перетину знаходиться проміж вершин, тобто на ребрі, і тоді знаходимо координати цієї точки:

$$
x_{j \Pi}=\frac{x_{j 1}+\lambda_{j} x_{j 2}}{1+\lambda_{j}} ; \quad y_{j \Pi}=\frac{y_{j 1}+\lambda_{j} y_{j 2}}{1+\lambda_{j}} ; \quad z_{j \Pi}=\frac{z_{j 1}+\lambda_{j} z_{j 2}}{1+\lambda_{j}}
$$

4. Знаходимо вершини, які знаходяться у рідині. Для цього вводимо додаткову, «базову» площину, паралельну площині $X O Y$, але розташовану значно нижче їі: $z=E$, де $E$ - довільне негативне число, яке по значенню має бути, як мінімум, на порядок більше за максимальний геометричний розмір ємності. Для такої площини коефіцієнти $A, B, C, D$ рівняння (2) мають такі значення:

$$
A_{\mathrm{B}}=0 ; \quad B_{\mathrm{B}}=0 ; \quad \mathrm{C}_{\mathrm{B}}=1 ; \quad \mathrm{D}_{\mathrm{B}}=-E
$$


«Системні технології» 2 (127) 2020 «System technologies»

Якщо вершина багатогранника $\left(x_{i}, y_{i}, z_{i}\right)$ знаходиться проміж площиною (3) та площиною (6), то добуток:

$$
F_{i}=\left(A_{p} x_{i}+B_{p} y_{i}+C_{p} z_{i}+D_{p}\right) \cdot\left(z_{i}+\mathrm{D}_{\mathrm{Б}}\right)
$$

буде негативним. Це означає, що вершина знаходиться в рідині. В протилежному випадку цей добуток буде позитивним.

5.3 отриманих точок перетину (для яких $\lambda_{j}>0$ ), та вершин багатогранника, які знаходяться у рідині (для яких $F_{i}<0$ ), формуємо новий масив координат точок, які представляють форму, заповнену рідиною.

6. По отриманих вершинах багатогранника, який представляє форму, заповнену рідиною, будуємо нову тріангуляцію Делоне (рис. 2).

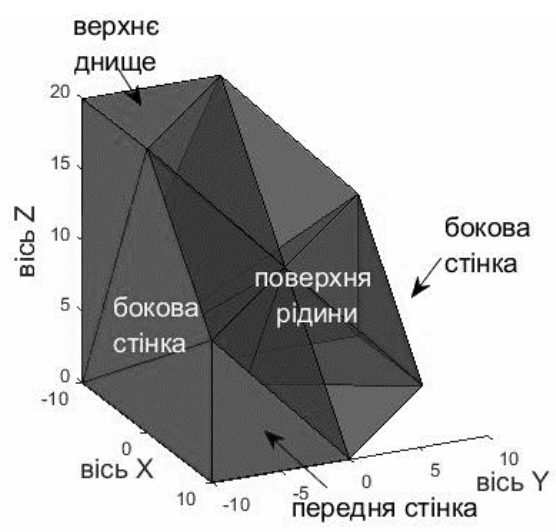

Рисунок 2 - Тріангуляція фігури, заповненою рідиною всередині паралелепіпеду

7. Знаходимо об’єм кожного з тетраедрів, що входять в нову тріангуляцію за формулою (де $k$ - номер тетраедра):

$$
V_{k}=\frac{1}{6}\left|\begin{array}{llll}
x_{k 1} & y_{k 1} & z_{k 1} & 1 \\
x_{k 2} & y_{k 2} & z_{k 2} & 1 \\
x_{k 3} & y_{k 3} & z_{k 3} & 1 \\
x_{k 4} & y_{k 4} & z_{k 4} & 1
\end{array}\right|
$$

8. Підсумовуючи об’єми усіх тетраедрів знаходимо об’єм всієї фігури:

$$
V=\sum_{k} V_{k}
$$

Це й є об’єм рідини, що знаходиться в нахиленій ємності. Його визначено за даними вимірювання: показаннями датчика рівня та інклінометра. 
«Системні технології» 2 (127) 2020 «System technologies»

Запропонований спосіб визначення кількості рідини було повністю алгоритмізовано та реалізовано в вигляді програмного забезпечення в середовищі MATLAB. В ході моделювання було підтверджено його дієздатність, ефективність та готовність до використання в вимірювальній техніці. На рисунку 2 ілюструється застосування способу визначення кількості рідини на основі тріангуляції для ємності, що має форму паралелепіпеду.

Даний спосіб можна вважати універсальним. Існуючі обмеження на його використання не мають практичного значення. По-перше, він не може бути використаний, коли поверхня рідини стає паралельною осі $Z$. Теоретично, віддаленням базової площини (збільшенням абсолютного значення $E$ ) можна досягти того, що розрахунок стає можливим за кутів нахилу максимально наближених до 90․ Проте на практиці наклони ємностей ніколи не перевищують 45 градусів. По-друге, в випадку наявності в ємності так званих застійних зон, в яких може залишатися рідина після того, як загальний рівень рідини зменшився, вочевидь приведе до помилки в розрахунку кількості рідини. Проте на практиці такі ємності для збереження рідини не використовуються. По-третє, якщо в ємності є об’єми, які ніколи не заповнюються рідиною (наприклад, тороїдальний бак), то під час розрахунку ці об’єми мають відраховуватися. Це має бути враховано один раз під час настроювання програмного забезпечення під конкретну задачу. Тоді вимірювання можна буде проводити так само автоматично.

Висновки. В результаті проведеного дослідження:

1) Розглянуто проблему визначення кількості рідини в нахиленій ємності, та, зокрема, задачу перерахунку даних вимірювання рівня висоти рідини та куту нахилу ємності в кількість рідини всередині ємності. Вказано на відсутність в науковій та технічній літературі відомостей щодо існування універсального способу її вирішення.

2) Знайдено спосіб визначення кількості рідини в нахиленій ємності на основі тріангуляції Делоне. Спосіб є універсальним та таким, що піддається автоматизації.

3) Для запропонованого способу розроблено алгоритм, який реалізовано в вигляді програмного забезпечення. В ході моделювання була 100 
«Системні технології» 2 (127) 2020 «System technologies»

підтверджена його дієздатність, ефективність та готовність до використання в вимірювальній техніці.

\section{ЛИТЕРАТУРА / ЛІТЕРАТУРА}

1. В.Б. Мазуренко Проблема визначення кількості рідини в рухомій ємності та можливі шляхи їі вирішення // Системні технології. Регіональний міжвузівський збірник наукових праць. - Випуск 4 (123). - Дніпро, 2019. C. $48-57$.

2. Бобровников Г. Н. Методы измерения уровня / Г. Н. Бобровников, А. Г. Катков. - М.: Машиностроение, 1977. - 167 с.

3. Бронштейн И.Н. Справочник по математике для инженеров и учащихся втузов / И.Н. Бронштейн, К.А. Семендяев. - М.: Наука, 1986. - 544 с.

4. Wei Xie, Xiaojing Wang, Huizhe Cui, Jun Chen. Optimization model of oilvolume marking with tilted oil tank // Open Journal of Optimization. - Vol.1 No.2, 2012. - P. 20 - 24.

5. Сабитов И. Х. Объёмы многогранников / И. Х. Сабитов. - М.: МЦНМО, 2002. -33 c.

6. Скворцов А.В. Триангуляция Делоне и её применение / А.В. Скворцов. - Томск: Изд-во Том. ун-та, 2002.- 128 с.

\section{REFERENCES}

1. Mazurenko V.B. A problem of measuring quantity of liquid inside moving tank and possible ways to resolve it // System technologies. Regional interuniversity compendium. - 4 (123). - Dnipro, 2019. - P. 48 - 57.

2. Bobrovnikov G. N. Methods of level measurement / G. N. Bobrovnikov. A.G. Katkov. - M.: Mashinostroyeniye. 1977. - 167 p.

3. Bronshteyn I.N. Math's reference for engineers and technical university students / I.N. Bronshteyn, K.A. Semendyaev. - M.: Nauka, 1986. - 544 p.

4. Wei Xie, Xiaojing Wang, Huizhe Cui, Jun Chen. Optimization model of oilvolume marking with tilted oil tank // Open Journal of Optimization. - Vol.1 No.2, 2012. - P. 20 - 24.

5. Sabitov I. H. Polyhedron Volumes / I. H. Sabitov. - M.:MCNMO, 2002. - 33p.

6. Skvortsov A.V. Delaunay triangulation and its application / A.V. Skvortsov. - Tomsk: Tomsk university publishing house, 2002.- 128 p.

\section{Способ определения количества жидкости в наклоненной емкости Accepted 19.02.2020}

Received 17.02.2020.

\section{на основе триангуляции Делоне}

Статья посвящена проблеме определения количества жидкости в наклонной емкости и, в частности, задаче пересчета данных измерения высоты уровня 


\section{«Системні технології» 2 (127) 2020 «System technologies»}

поверхности жидкости и угла наклона емкости в количество жидкости внутри емкости. Универсальное решение этой задачи в научной и технической литературе до настоящего времени не представлено. Для определения количества жидкости автором предложен способ на основе триангуляции Делоне. Показано, что для практических целей данный способ является универсальным и поддается автоматизации.

\section{$A$ method based on Delaunay triangulation to determine the amount of liquid inside an inclined tank}

There is a problem of determining the amount of liquid inside an inclined tank that appears as an additional measurement error provided by difference in conditions when a level sensor graduation is being obtained and when the level sensor graduation is being applied. The additional error doesn't exist only in the case if a cross-sectional area doesn't depend on the crosssection height and if the sensor is located exactly in the geometrical center of cross-section. In the rest cases this additional error could be eliminated if the liquid amount calculation includes the tank inclination data. But until now a method how to do this kind of calculation has not been presented in scientific and technical sources. From math point of view, it is as a calculating volume of 3D figure. That is why, various manner of calculating volume are analyzed to determine which one is more suitable for solving problem of determining the amount of liquid inside an inclined tank. Most of them require participation of specialist in geometry every time when we are receiving measurement data and having need to estimate liquid amount. There is no process automatization, thus such methods are not for practical measurement. The author made a conclusion that the most appropriate method to solve the problem is using the Delaunay 3D triangulation. It is suggested to determinate the tank shape as a polyhedron that could be an exact representation of the tank shape in case if the tank shape is also polyhedron or an approximation if the tank shape is arbitrary. Then Delaunay 3D triangulation for that polyhedron should be applied to split the polyhedron into set of tetrahedrons. The equation that describes liquid surface plane could be obtained from measurement data such as an inclination angle and a level height supported by level sensor coordinates. After that it becomes possible to find points of intersection of liquid surface plane and edges of tetrahedrons. The next step is that vertexes of a new polyhedron that represents shape of figure filled by liquid must be determined. These vertexes are intersection points and all vertexes of original tank polyhedron which are beneath the liquid surface plane. The Delaunay 3D triangulation shall be applied once more time but now it is applied to the new polyhedron. New set of tetrahedrons is formed. Volumes of each tetrahedron from the new set could be calculated by simple formula and then these volumes must be summed up. This sum is the sought amount of liquid inside an inclined tank. All mentioned above action are performed by coordinate geometry methods. A full set of necessary formulas and equations are presented in the article.

Мазуренко Валерий Борисович - Днепровский национальный университет им. О.Гончара, к.т.н., доцент кафедры радиоэлектронной автоматики.

Мазуренко Валерій Борисович - Дніпровський національний університет університет ім. О.Гончара, к.т.н., доцент кафедри радіоелектронної автоматики.

Mazurenko Valeriy - Oles Honchar Dnipro National University, Doctor of Philosophy, docent of Chair of Radioelectronic Automation. 